\title{
OBTAINING NEW THIN WALLED TUBULAR STRUCTURES THROUGH MATRIX MORPHOLOGICAL RESEARCH
}

\author{
VLAD ANDREI CIUBOTARIU ${ }^{* 1}$, CRINA MARIA RADU ${ }^{1}$, COSMIN GRIGORAȘ $^{1}$, \\ EUGEN HERGHELEGIU ${ }^{1}$
}

I "Vasile Alecsandri" University of Bacau, Calea Marasesti 157, Bacau, 600115, Romania

\begin{abstract}
New products based on a structure that represents a combination of known elements in a higher quality set, as well as products that refer to new shapes, new curves, new surfaces can be obtained logically - analytically - deductively or by methods specific to the optimal calculation. The present paper focuses on the method of analyzing tridimensional morphology, some possible solutions being evaluated on value criteria. Of course, these methods can be applied in the field of engineering with very good results. The focus of this study is to obtain new thin walled tubular structures - such as car crash members - which in the case of axial shock loads have a higher predictable behavior compared to those already used in various technical fields. Following the study, it can be said that depending on the amount of absorbed energy in the case of axial collisions and the absorption of kinetic energy developed at the time of impact, the optimal crashworthiness solution could be tubular structures with a circular support base and rectangular deformable area for impact.
\end{abstract}

Keywords: tridimensional morphology, tubular structures, crash test, crashworthiness

\section{INTRODUCTION}

Innovation gains vital emphasis even for highly developed industrialized countries, and the conquest of international markets, in the face of fierce competition, is only possible through the creation of "super-products". Thus, this goal is unattainable without an intensification of technical creation activities. Over a period of 10 years, Japan Research Development Corporation has examined more than 3,000 pre-selected patents, of which it has retained only 300 , and of these, only about 100 have led to super-products and super-technologies [1].

Since for each technical problem there can be a lot of solutions, the group of new solutions includes a multitude of incompatible, divergent, dissonant, unusable solutions, but also many viable solutions, of which only a very small part are viable-efficient solutions at the historical-technologically given moment. New products based on a structure that represents a combination of known elements in a higher quality set, as well as products that refer to new shapes, new curves, new surfaces can be obtained logically - analytically - deductively or by methods specific to the optimal calculus [2]. The present paper will focus on the method of tridimensional morphology analysis, some possible solutions being evaluated on value criteria.

Of course, these methods can be applied in the field of engineering with very good results. For example, thinwalled tubular structures are used in the automotive industry to achieve the elements necessary for the absorption of energy developed in the event of collisions and the absorption of kinetic energy, keeping the level of the response force sufficiently low.

\footnotetext{
${ }^{*}$ Corresponding author, email: vlad.ciubotariu@ub.ro

(C) 2021 Alma Mater Publishing House
} 
From the specific literature on the fundamental theory of the characteristic design of components and structures subjected to controlled deformations [3], the impact force transferred to the resistance structure of the vehicle must be less than the force causing permanent deformations of the safety space (Figure 1) [4]. In real applications, such an impact energy absorbing system can be made of thin-walled tubular structures, such as, for example, rectangular tubes (Figure 2) [5]. They are widespread in the automotive industry, meeting the objectives of impact behavior quite well, protecting both the occupants of the vehicle and its structure itself [6].

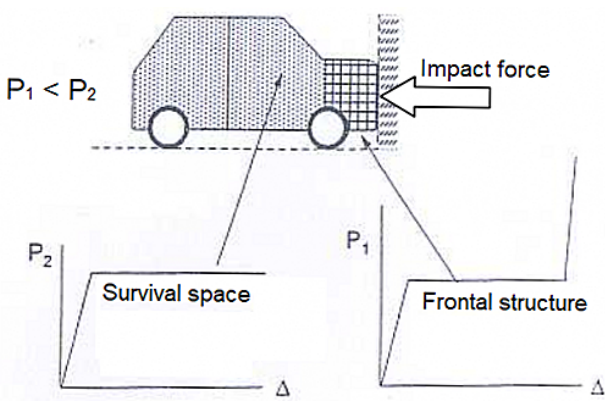

Fig. 1. Typical crash characteristics of crashworthy structures [3].

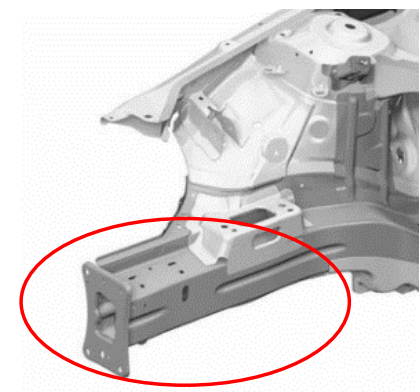

Fig. 2. Impact energy absorbing system using rectangular tubes [7].

Structures that absorb impact energy must deform in a predictable manner, with a controlled level of the maximum force to which the structure yields. Also, in order to efficiently describe the impact energy absorption capacity, some qualitative criteria must be met. These criteria are used in the initial stages in the design and construction of structures for the absorption of impact energy. Some of the main criteria for assessing the absorption capacity of impact energy or crashworthiness are presented below.

Response force $F_{\max }$ is the force / displacement response of thin-walled tubular structures.

Absorbed energy $E_{a}[3]$ is defined as the integrated curve of the force $F$ in relation to the displacement $d$, according to the expression:

$$
E_{a}=\int_{0}^{\delta_{\max }} F \cdot \delta d \delta
$$

where $F$ is the instantaneous deformation force, $\delta$ is the instantaneous distance and $\delta_{\max }$ is the maximum deformation distance.

The capacity of specific energy absorption $S_{e a}$ is the most important element describing a structure. The $S_{e a}$ parameter is most commonly used to characterize thin-walled tubular structures, given the problem of reducing the weight of different assemblies. This subunit index is defined by the energy absorbed per unit mass, where $E_{a}$ is the energy absorbed and $m$ is the mass of the initial structure [3]:

$$
S_{e a}=\frac{E_{a}}{m}
$$

Mean deformation force $F_{m}$ for a given deformation, is defined as the ratio between the total absorbed energy $E_{t}$ and the total deformation $\delta_{\max }$ [8], according to the relation below:

$$
F_{m}=\frac{E_{t}}{\delta_{\max }}
$$

Deformation force efficiency $E_{F}$ is an important parameter in assessing the uniformity of deformation forces for different structures. For an ideal thin-walled structure, this parameter should tend to $100 \%$ [3]. The parameter is calculated on the basis of the ratio between the mean force $F_{m}$ and the response force $F_{\max }$ exerted on a thin-walled structure, as follows:

$$
E_{F}=\frac{F_{m}}{F_{\max }} \cdot 100 \%
$$




\section{MATRIX MORPHOLOGICAL ANALYSIS AND SIMULATION SETUP}

\subsection{Description of the method regarding the analysis of tridimensional morphology}

There are situations where combinations of elements of three or more feature groups are used. In this case the possible combinations are inscribed in tridimensional or space matrices. In other cases, even more feature groups are used, and their analysis is all the more difficult the larger the matrix size is [1].

Under these conditions, the tridimensional morphological method is used, constructing a cylindrical matrix. The essence of the method is to transpose the problem to be solved into a morphological ensemble by breaking it down into component parts (physical or functional) and establishing for each component the possible solutions.

The aim of the present paper is to obtain new thin-walled tubular structures - such as car side members (Figure 3) - which in the case of impact loads have a higher predictable behavior compared to those already used in various technical fields. Thus, for a proper and comprehensive characterization, the following forming assemblies were determined: A - section shape, B - wall appearance, C - generating geometry. For each set a certain number of constructive possibilities are identified. The obtained morphological ensemble matrix is presented in Table 1. The total number of combinations that can be obtained between these solutions is $\mathrm{N}=4 \times 6 \times 5=120$.

All these $\mathrm{N}$ possible solutions constitute the cylindrical matrix shown in Figure 4. In this cylindrical matrix the classification according to the three criteria is performed axially $\left(\mathrm{A}_{1}, \mathrm{~A}_{2}, \mathrm{~A}_{3}, \mathrm{~A}_{4}\right)$, radially $\left(\mathrm{B}_{1}, \mathrm{~B}_{2}, \mathrm{~B}_{3}, \mathrm{~B}_{4}, \mathrm{~B}_{5}, \mathrm{~B}_{6}\right)$ and tangentially $\left(\mathrm{C}_{1}, \mathrm{C}_{2}, \mathrm{C}_{3}, \mathrm{C}_{4}, \mathrm{C}_{5}\right)$.

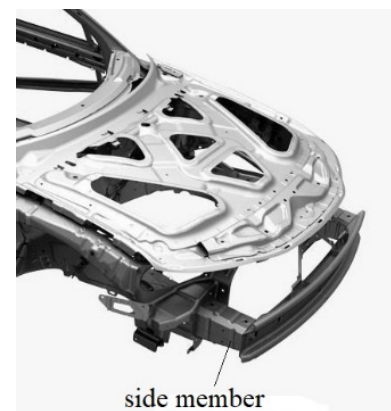

Fig. 3. Car side members [9].

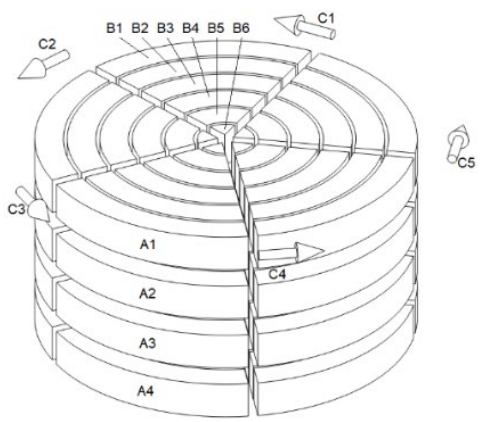

Fig. 4. Cylindrical matrix.

Table 1. Morphological ensemble matrix.

\begin{tabular}{|c|c|c|}
\hline $\begin{array}{c}\text { A } \\
\text { section shape }\end{array}$ & $\begin{array}{c}\text { B } \\
\text { wall appearance }\end{array}$ & $\begin{array}{c}\mathrm{C} \\
\text { generating geometry }\end{array}$ \\
\hline 1. constant & 1. simple & 1. rectangular polygon \\
\hline 2. linear variable (conical) & 2. corrugated & 2. hexagonal polygon \\
\hline 3. nonlinear variable (1 level) & 3. symmetrically stamped & 3. mixed polygonal geometries \\
\hline 4. nonlinear variable (2 levels) & 4. asymmetrically stamped & 4. circle \\
\hline- & 5. with symmetrical indentations & 5. mixed geometries \\
\hline- & 6. with asymmetrical indentations & - \\
\hline
\end{tabular}

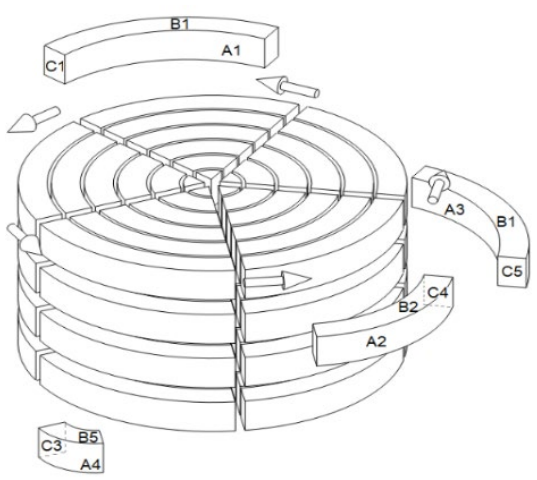

Fig. 5. Different combinations extracted from the cylindrical matrix. 
Each combination $\left(\mathrm{A}_{\mathrm{i}} \mathrm{B}_{\mathrm{j}} \mathrm{C}_{\mathrm{k}}\right)$ between the possible solutions for the construction of the thin-walled tubular structure represents a theoretical alternative to solve the given problem. All these combinations must be analyzed separately. Some of these solutions are already implemented, for example $\mathrm{A}_{1} \mathrm{~B}_{1} \mathrm{C}_{1}$ combination, some are currently impossible or incompatible (ex: $\mathrm{A}_{4} \mathrm{~B}_{2} \mathrm{C}_{5}$ combination), and some are compatible (ex: $\mathrm{A}_{4} \mathrm{~B}_{5} \mathrm{C}_{4}$ combination) and can be put into practice immediately or in perspective, depending on the value analysis of the new structure.

For example, in addition to the compatible solution, already used in industry, three more potential solutions for value analysis were extracted, as follows: $A_{1} B_{1} C_{1}, A_{2} B_{2} C_{4}, A_{3} B_{1} C_{5}, A_{4} B_{5} C_{3}$ (Figure 5). The constructive models obtained based on these combinations are presented in the Figures 6.a-d.

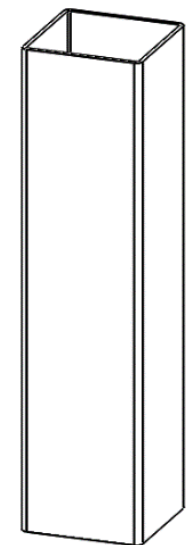

a. $\mathrm{A}_{1} \mathrm{~B}_{1} \mathrm{C}_{1}$

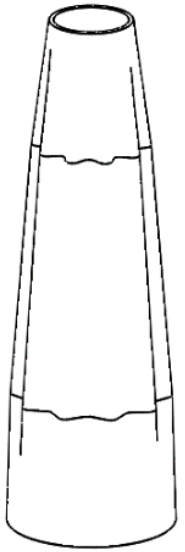

b. $\mathrm{A}_{2} \mathrm{~B}_{2} \mathrm{C}_{4}$

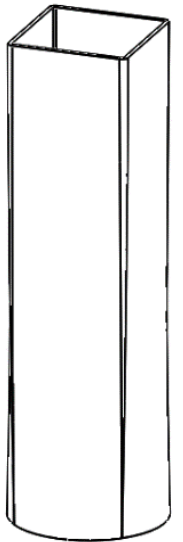

c. $\mathrm{A}_{3} \mathrm{~B}_{1} \mathrm{C}_{5}$

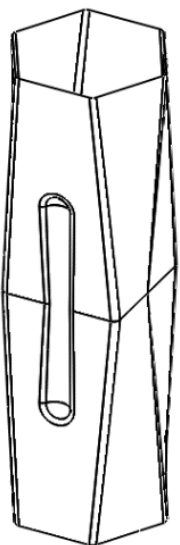

d. $\mathrm{A}_{4} \mathrm{~B}_{5} \mathrm{C}_{3}$

Fig. 6. Potential solutions extracted from $\mathrm{N}$ combinations.

\subsection{Numerical study}

Ansys Mechanical finite element analysis software was used to perform conclusive simulations on the behavior during the collapse of thin-walled tubular structures.

This software is used to simulate computer models of structures, electronics, or machine components for analyzing strength, toughness, elasticity, temperature distribution, electromagnetism, fluid flow, and other attributes. Ansys structural analysis software solves complex structural engineering problems in order to make better, faster design decisions. Easily connection to other physics analysis tools for even greater fidelity is possible. Ansys structural analysis software is used across industries to help engineers optimize their product designs and reduce the costs of physical testing [10].

Using this software, the dynamic loading of the thin-walled structures chosen to be compared was simulated. By using the Explicit Dynamics module, it was considered that a mass body $m$, falls freely from a height $h$, axially crashing the structure which is fixed to the ground. Table 2 presents all the characteristics considered for these simulations.

Table 2. Characteristics taken into account for performing the simulations.

\begin{tabular}{|c|l|c|c|c|}
\hline Nr. & \multicolumn{1}{|c|}{ Characteristic } & Symbol & Unit & Value \\
\hline 1. & Ram mass & $\mathrm{m}$ & {$[\mathrm{kg}]$} & 120 \\
\hline 2. & Distance between structure and ram & $\mathrm{h}$ & {$[\mathrm{mm}]$} & 2100 \\
\hline 3. & Fall time to impact & $\mathrm{t}$ & {$[\mathrm{s}]$} & 0.654 \\
\hline 4. & Speed developed at impact & $\mathrm{v}$ & {$[\mathrm{m} / \mathrm{s}]$} & 6.418 \\
\hline 5. & Kinetic energy developed on impact & $\mathrm{E}_{\mathrm{c}}$ & {$[\mathrm{J}]$} & 2471.276 \\
\hline 6. & Structure material & $\mathrm{AL} 6061-\mathrm{T} 6$ & - & - \\
\hline 7. & Structure height & $\mathrm{h}_{\mathrm{s}}$ & {$[\mathrm{mm}]$} & 190 \\
\hline & & & & $\mathrm{A}_{1} \mathrm{~B}_{1} \mathrm{C}_{1}-0.0937$ \\
$\mathrm{~A}_{2} \mathrm{~B}_{2} \mathrm{C}_{4}-0.0846$ \\
$\mathrm{~A}_{3} \mathrm{~B}_{1} \mathrm{C}_{5}-0.0937$ \\
$\mathrm{~A}_{4} \mathrm{~B}_{5} \mathrm{C}_{3}-0.0977$
\end{tabular}




\section{RESULTS AND DISCUSSION}

\subsection{Comparative structures}

Following the simulations performed on all four thin-walled tubular structures, the graphs corresponding to their plastic deformation were obtained (Figure 7.a-d), as well as force / displacement response diagrams, as shown in Figure 8. Applying equations (1)-(4) it was possible to obtain the absorbed energy / displacement response diagram (Figure 9), as well as other parameters necessary for the value analysis of the four studied structures.

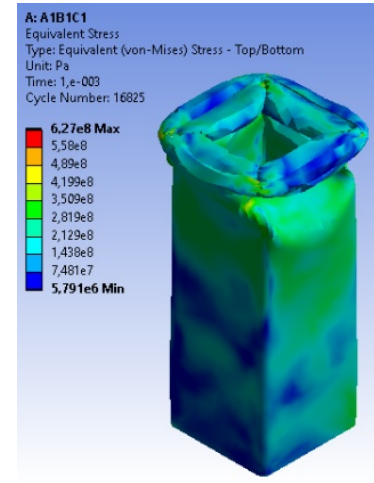

a. $\mathrm{A}_{1} \mathrm{~B}_{1} \mathrm{C}_{1}$

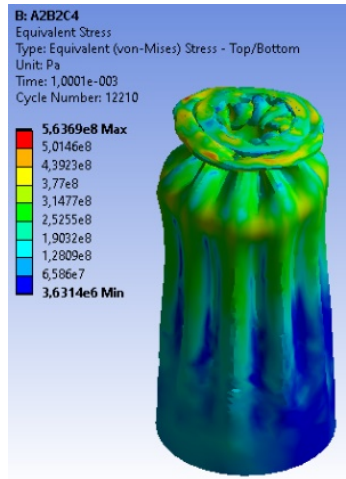

b. $\mathrm{A}_{2} \mathrm{~B}_{2} \mathrm{C}_{4}$

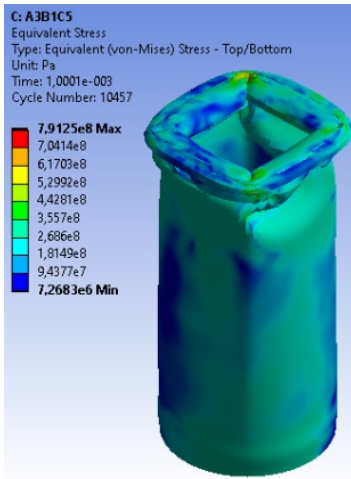

c. $\mathrm{A}_{3} \mathrm{~B}_{1} \mathrm{C}_{5}$

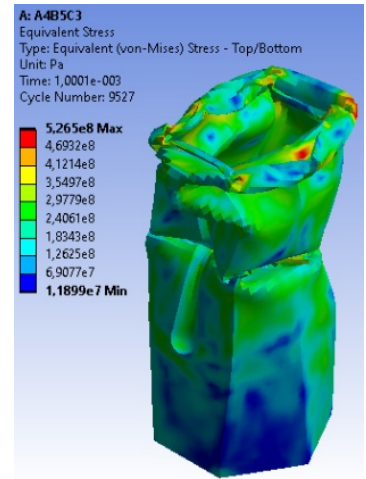

d. $\mathrm{A}_{4} \mathrm{~B}_{5} \mathrm{C}_{3}$

Fig. 7. Crash test simulation results on thin-walled tubular structures.

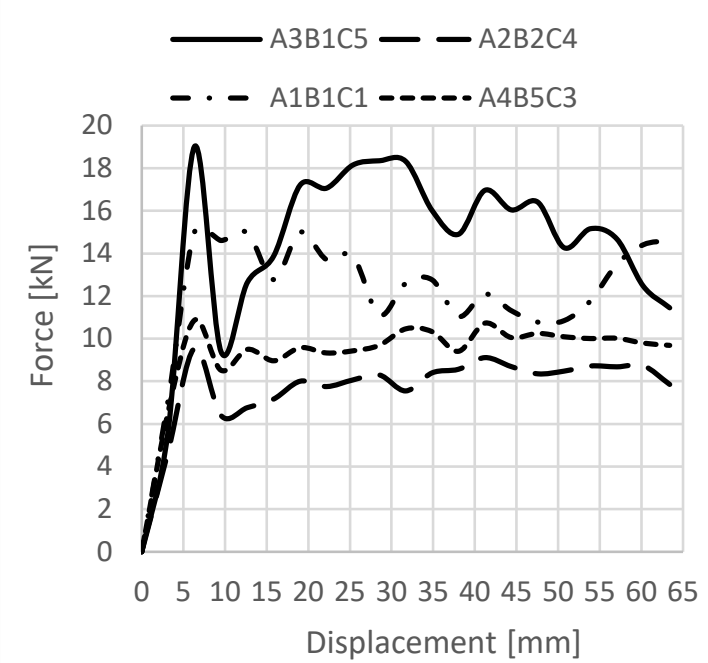

Fig. 8. Force / displacement response diagram for all four thin-walled tubular structures.

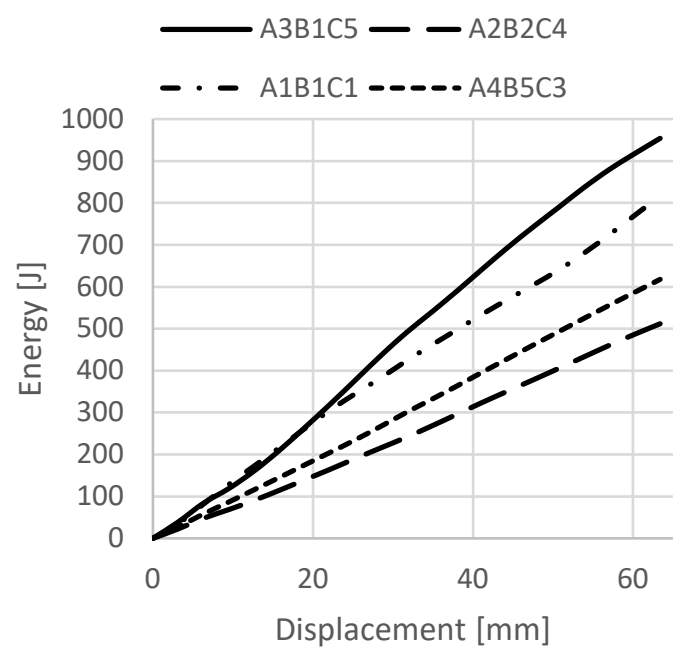

Fig. 9. Absorbed energy / displacement response diagram for all four thin-walled tubular structures.

\subsection{Value analysis}

To increase the degree of objectivity in selecting the optimal solution, a subunit coefficient in round brackets is assigned to each combination from the morphology $\mathrm{ABC}$, so that the sum of the coefficients on a line is equal to 1 (Table 3). The solution with the maximum weight thus obtained is the $\mathrm{A}_{3} \mathrm{~B}_{1} \mathrm{C}_{5}$ combination with the weight 0.4 $+0.4+0.4+0.1=1.3$. Table 3 shows the values obtained for the studied structures. From this value assessment it can be seen that the solution already used in the industry has also quite good characteristics. Obviously, for the implementation of such a solution requires much more data and calculations both economic and technological.

Table 3. Objectivity coefficients associated with each solution combination.

\begin{tabular}{|c|l|c|c|c|c|}
\hline No. & \multicolumn{1}{|c|}{ Criterion } & $\mathrm{A}_{1} \mathrm{~B}_{1} \mathrm{C}_{1}$ & $\mathrm{~A}_{2} \mathrm{~B}_{2} \mathrm{C}_{4}$ & $\mathrm{~A}_{3} \mathrm{~B}_{1} \mathrm{C}_{5}$ & $\mathrm{~A}_{4} \mathrm{~B}_{5} \mathrm{C}_{3}$ \\
\hline 1. & Absorbed energy $E_{a}[\mathrm{~J}]$ & $816.8(0.3)$ & $511.76(0.1)$ & $954.03(0.4)$ & $617.7(0.2)$ \\
\hline 2. & Specific energy absorption $S_{e a}$ & $8.72(0.3)$ & $6.05(0.1)$ & $10.18(0.4)$ & $6.32(0.2)$ \\
\hline 3. & Mean deformation force $F_{m}[\mathrm{kN}]$ & $12.88(0.3)$ & $8.07(0.1)$ & $15.05(0.4)$ & $9.74(0.2)$ \\
\hline 4. & Deformation force efficiency $E_{F}$ & $0.86(0.3)$ & $0.84(0.2)$ & $0.79(0.1)$ & $0.9(0.4)$ \\
\hline
\end{tabular}




\section{CONCLUSIONS}

Using logical / analytical / deductive methods, new shapes of thin-walled tubular structures can be obtained, so that they behave in an anticipated manner depending on the type of applied stress.

Thus, the analysis of tridimensional morphologies, in this case being cylindrical matrices, proved to be an interesting and efficient method in obtaining new structures. It is noted that this method is somehow time consuming given that there are many combinations to check, but this is not the subject of this paper.

The analytical study through numerical simulations are the first step in anticipating the behavior of this type of structures, providing the information necessary for a corresponding value analysis. Also, through the Explicit Dynamics module available on the Ansys software, important information can be obtained regarding the manner of plastic deformation during shock loading.

Therefore, it can be said that depending on the amount of energy absorbed in the case of axial collisions and the absorption of kinetic energy developed at the time of impact, keeping the level of response force low enough, the optimal solution is represented by structures with circular base and rectangular impact area, which in this case that would be $\mathrm{A}_{3} \mathrm{~B}_{1} \mathrm{C}_{5}$ combination.

\section{REFERENCES}

[1] Paicu, G., Creativitatea - fundamente, secrete și strategii, 2nd edition, Ed. PIM, Iași, 2011.

[2] Belous, V., Manualul inventatorului - sinteza creativă în tehnică, Ed. Tehnică, București, 1991.

[3] Zaini, A., Impact and energy absorption of empty and foam-filled conical tubes, Ph.D. thesis, Queensland University of Technology, Australia, 2009.

[4] Nagel, G.M., Dynamic simulation and energy absorption of tapered thin-walled tubes under oblique impact loading, International Journal of Impact Engineering, vol. 32, no. 10, 2006, p.1595-1620.

[5] Putra, I.S., Dirgantara, T., Anh, L.H., Homma, H., Kishimoto, K., Behavior of thin-walled square tube and tubular hat sections subjected to low velocity impact loading, Advanced Materials Research, vol. 33-37, 2008, p. 387-394.

[6] Peroni, L., Avalle, M., Belingardi, G., Comparison of the energy absorption capability of crash boxes assembled by spot-weld and continuous joining techniques, International Journal of Impact Engineering, vol. 36, no. 3, 2009, p .498-511.

[7] https://www.carbodydesign.com/gallery/2012/05/audi-a3-design-story/37/ (05.08.2020).

[8] Zarei, H.R., Kroger, M., Multiobjective crashworthiness optimization of circular aluminum tubes, International Journal of Crashworthiness, vol. 12, no.3, p.301-308, 2007.

[9] https://www.cgtrader.com/3d-models/vehicle/part/car-frame (05.08.2020).

[10] https://www.ansys.com/products/structures (05.08.2020). 